\title{
DEVELOPMENT OF NEW ITERATIVE SCHEME FOR SOLVING NON-LINEAR EQUATIONS
}

\author{
Tusar singh ${ }^{1}$ and Dwiti Behera ${ }^{1}$ \\ ${ }^{1}$ Ravenshaw University
}

October 31, 2021

\begin{abstract}
Within our study a special type of 【iterative method】 ^ $\omega$ is developed by upgrading Newton-Raphson method. We have modified Newton's method by using our newly developed quadrature rule which is obtained by blending Trapezoidal rule and open type Newton-cotes two point rule. Our newly developed method gives better result than the Newton's method. Order of convergence of our newly discovered quadrature rule and iterative method is 3 .
\end{abstract}

\section{Hosted file}

tusar_2210.docx available at https://authorea.com/users/443832/articles/543733-developmentof-new-iterative-scheme-for-solving-non-linear-equations 